\title{
Epistemic instrumentalism, permissibility, and reasons for belief
}

\author{
Asbjørn Steglich-Petersen \\ Aarhus University \\ Forthcoming in: \\ Conor McHugh, Jonathan Way and Daniel Whiting (eds.) \\ Normativity: Epistemic and Practical \\ Oxford University Press
}

\begin{abstract}
Epistemic instrumentalists seek to understand the normativity of epistemic norms on the model practical instrumental norms governing the relation between aims and means. Non-instrumentalists often object that this commits instrumentalists to implausible epistemic assessments. I argue that this objection presupposes an implausibly strong interpretation of epistemic norms. Once we realize that epistemic norms should be understood in terms of permissibility rather than obligation, and that evidence only occasionally provide normative reasons for belief, an instrumentalist account becomes available that delivers the correct epistemic verdicts. On this account, epistemic permissibility can be understood on the model of the wide-scope instrumental norm for instrumental rationality, while normative evidential reasons for belief can be understood in terms of instrumental transmission.
\end{abstract}

Keywords: Epistemic instrumentalism, reasons for belief, instrumental rationality, doxastic norms, evidence.

\section{Introduction}

Many philosophers have thought there to be a distinctive kind of normativity 'theoretical' or 'epistemic' normativity - peculiar to the evaluation of beliefs. Beliefs, we are told, are subjects only to epistemic norms that make the evaluation of beliefs depend entirely on their epistemic properties, such as their truth, relationship to the evidence, or coherence with other held beliefs. These norms are seen as isolated from non-epistemic concerns, and as unavailable for explanation in terms of non-epistemic norms. To the 'intrisicalists', as I shall follow Cowie (2014) in calling them, epistemic norms rather form an independent sui generis domain of normativity, intrinsic to the nature of belief, and separate from the general domain of practical normativity governing other kinds of attitudes and conduct. ${ }^{1}$

Others have found it peculiar that the evaluation of beliefs should be seen as isolated in this way. Granting that epistemic norms in some sense do seem authoritative over beliefs, they have sought to nevertheless understand these norms as parts or special instances of the broader set of practical norms. A main motivation for this is theoretical simplicity as far as the normative goes. It would be theoretically attractive if normativity formed a unity rather than consisting of distinct and isolated domains, that would each require their own peculiar theory, and make it difficult or impossible to make normative comparisons across domains. Another main motivation is the difficulty of coming up with enlightening explanations of epistemic normativity, that would face us if we cannot appeal to the general practical human concerns and interests that underlie other kinds of norms. It is hard to see why we should care about conforming to the norms of epistemic normativity if these are disconnected to anything else that we care about.

\footnotetext{
1 Philosophers endorsing versions of the intrinsicalist account of epistemic normativity include Scanlon (1998), Adler (2002), Kelly (2003), Shah (2003), Engel (2004), Wedgwood (2007), Parfit (2011), Fassio (2011), Whiting (2013), and more.
} 
A particularly popular and attractive instance of this unifying effort seeks to understand epistemic norms as species of instrumental norms. ${ }^{2}$ Setting certain complications aside, such norms compel us to take the necessary or best means to our aims, or to the aims that we ought to pursue. Roughly speaking, epistemic instrumentalists claim that epistemic norms concern how one should form and regulate one's beliefs if they are to serve an epistemic aim, for example the aim of believing the truth about some subject matter, which may in turn serve other aims of a more practical nature.

Some have been attracted to instrumentalism by the promise of a more sweeping kind of theoretical simplicity than the one described above, namely integration with our best scientific understanding of the world, or a 'naturalistic' world-view. Whereas the kind of categorical normativity that intrinsicalists often ascribe to epistemic norms seems resistant to scientific understanding, instrumental norms are hypothetical, and thus, some contend, reducible to certain descriptive relations between aims and means. If epistemic norms could be understood as purely instrumental norms, this would thus allow naturalists to hold on to the existence of epistemic norms, even if the reality of other kinds of norms is rejected. ${ }^{3}$

But one needn't be motivated by naturalist concerns to find the instrumentalist account attractive. Indeed, what I regard as the most plausible version of epistemic instrumentalism is not necessarily much friendlier to naturalism, than the theories postulating a sui generis domain of categorical epistemic normativity. This version of instrumentalism leaves open that instrumental epistemic norms attain categorical force in cases where there is categorical reason to promote the relevant epistemic aims. For example, I might plausibly have categorical reason to seek a true belief as to whether my chemical lawn-repair kit has harmful effects on the environment before spraying it on my lawn, in which case I would also be categorically required to take means for attaining such a belief, for example by seeking out and conforming my belief to adequate evidence on the matter. When seen in isolation, epistemic norms simply concern the regulation of belief on the condition that it is to promote the aim of believing truly, which is a purely instrumental matter. But just like other instrumental norms integrate with wider norms concerning which aims to adopt and which not to, the epistemic norms also gain weight from wider practical norms about which matters one should seek the truth about. While this sort of account may frustrate naturalistic aspirations, it still holds the promise of unifying epistemic normativity with a relatively well-understood species of practical normativity - instrumental normativity - that integrates with the wider domain of practical normativity in a non-mysterious way.

Instrumentalists typically seek to be non-revisionary in the sense of explaining our ordinary epistemic assessments in a way that leaves those assessments more or less intact. But this is easier said than done, since instrumentalists make epistemic evaluations dependent on aims. Predictively, the central objections to the instrumentalist account has therefore been that the aims on which epistemic norms are claimed to depend are too few to explain all of the epistemic reasons that we intuitively seem to have, and, conversely, that these aims generate certain epistemic reasons that we do not intuitively seem to have. We can refer to these two objections as the 'Too Few Reasons Objection', and the 'Too Many Reasons Objection', respectively, to adopt the terminology recently coined by Côté-Bouchard (2015).

\footnotetext{
2 Philosophers endorsing versions of the instrumentalist account of epistemic normativity include Quine (1969), Foley (1987), Nozick (1993), Kitcher (1992), Giere (1989), Papineau (1999), Cowie (2014), and Steglich-Petersen (2011a).

${ }^{3}$ For a general argument that categorical normativity is incompatible with a scientific world-view, see e.g. Mackie (1979). For naturalistically motivated instrumentalism, see e.g. Quine (1969) and Papineau (1999).
} 
In this paper I seek to develop a version of the instrumentalist account that answers these objections, and, more broadly, delivers the intuitively correct epistemic verdicts. After outlining the Too Few Reasons Objection in Section 2, I show in Section 3 how the force of the objection presupposes an understanding of evidential norms that is becoming increasingly unpopular, even among intrinsicalists, according to which evidence on its own can make the case that one ought or have positive reason to adopt some particular belief, rather than merely determining the permissibility of belief. In Section 4, I turn to argue that once we realize this, an instrumentalist account becomes available that delivers the correct epistemic verdicts. To be specific, I argue that epistemic permissibility can be understood on the model of the wide-scope norm of instrumental rationality. Cases where the evidence provide reasons going beyond mere permissibility, or even obligate belief, can be understood on the model of instrumental transmission of reasons from aims to means.

\section{The Too Few Reasons Objection}

Epistemic instrumentalism is often formulated as a view about epistemic reasons: there is epistemic reason for $\mathrm{S}$ to believe that $\mathrm{p}$ only if $\mathrm{S}$ has some aim or desire that would be promoted by believing p. As will become clear later on, I think that the terminology of 'reasons' captures a more limited part of our epistemic assessments than this formulation of instrumentalism suggests, but I will go along with it for now. The Too Few Reasons Objection point out that there are cases in which we seem to have epistemic reason to believe some proposition, even if believing that proposition would not promote any held desire or aim. Such cases usually divide into cases where the agent is completely indifferent about having the relevant true belief, in the sense that no desire or aim of the agent would be promoted or affected, and cases where the agent has aims or desires that a true belief about the relevant matter would frustrate or detract from. I follow Côté-Bouchard (2015) in calling the first kind cases of epistemic indifference, and the second kind cases of truth-avoidance. There is an abundance of cases of either kind in the literature.

For cases of epistemic indifference, suppose that you, without wanting it, are provided conclusive evidence that the number of dust specs on your desk is even; or of what the $323^{\text {rd }}$ entry in the Wichita phone directory is; or that the state beverage of Delaware is milk. In short, conclusive evidence about a proposition that you couldn't care less about. In these cases, it has seemed to many that adequate evidence provides you with good epistemic reason to believe the relevant proposition, even if having such a true belief wouldn't promote any aim or desire of yours.

For cases of truth-avoidance, consider Kelly's (2003) case of being about to watch a suspense thriller when someone in your presence gives away the ending. Here it seems that you are provided with good epistemic reason to form a belief as to how the movie ends, even if you would prefer not to have such a belief. These cases thus appear to be counterexamples to instrumentalism: we seem to have more epistemic reasons than the instrumentalist can account for.

A number of strategies have been adopted in response. ${ }^{4}$ One strategy would be to simply deny the alleged datum that we really do have normative epistemic reason to believe in cases where no aims of ours would be promoted (e.g. Olson 2011), or claim that if there are such reasons, they are reasons only in a non-normative sense, analogous to the way in which etiquette might be though to generate 'reasons' (cf. Hattiangadi

\footnotetext{
${ }^{4}$ For a helpful catalogue and discussion of possible responses to the Too Few Reasons Objection, which I rely on here, see Côté-Bouchard (2015).
} 
2007). As will become clear in the next section, I agree with this strategy in thinking that the objection to some extent relies on a misrepresentation of our normative intuitions.

Others accept the datum and try to locate senses in which there is an underlying aim or desire to explain it after all. For example, Schroeder (2007) argues that because of the interconnectedness of beliefs, any false belief can lead to other false beliefs, thus creating a risk of frustrating our aims, whether practical or epistemic, even if the initial false belief taken in isolation does not. According to Schroeder, this means that we have instrumental reason to ensure true belief and avoiding error with respect to any proposition, however insignificant they may initially seem. But as McPherson (2012) has pointed out, this argument leads to an explosion of instrumental reasons, because the notion of significance that it relies on is so weak. Any action we might take will have some very low degree of potential significance with respect to the promotion or frustration of any other aim, but we don't usually take such a low degree of significance to generate instrumental reasons.

Another strategy relies on the idea that beliefs are essentially regulated by an aim of truth, such that whenever we believe that $\mathrm{p}$, that belief is under the regulation of an aim of believing $p$ truly. ${ }^{5}$ The attraction of this strategy is that it guarantees the presence of the relevant aim whenever we hold a belief. However, while this idea may well stand to explain certain phenomena concerning the formation and regulation of beliefs (I will return to this later on), many find it unable to account for the sort of reasons at stake in the Too Few Reasons Objection. As Côté-Bouchard (2015) points out, such an aim would only be present when the relevant belief is actually held, but in the problematic cases there is reason to take up a belief that is not yet held. It is also doubtful that there is a plausible version of the idea of an essential truth-aim that is sufficiently strong to ground the kind of normativity we at least sometimes take epistemic reasons to possess. Intentional aims of agents might be up for that task. But if any beliefs are under the regulation of an agent's intentional aims, this will only be a small subset, leaving the vast majority of our beliefs to regulation by naturally selected sub-intentional mechanisms that by contrast are ill suited to ground the kind of epistemic reasons at stake.

Cases of epistemic indifference and truth-avoidance also appear to be counterexamples to instrumentalist accounts of epistemic normativity that allow facts about what aims ought to be adopted to play a role. According to such accounts, $\mathrm{S}$ having epistemic reason to believe that $\mathrm{p}$ does not require that $\mathrm{S}$ has an actual aim or desire that would be promoted by believing $\mathrm{p}$ truly, but merely requires that $\mathrm{S}$ ought or has reason to adopt such an aim, for example because promoting the aim would be practically valuable or morally required. But what value or moral requirement would be served by having true beliefs about extremely trivial propositions, such as the one concerning the number of dust specs on my desk? And shouldn't we, other things being equal, find it an unhappy outcome if someone prematurely came to know the ending of a suspense thriller?

\footnotetext{
${ }^{5}$ For discussion, see Williams (1973), Velleman (2000), Wedgwood (2002), Shah (2003), Steglich-Petersen (2006a; 2006b; 2008a; 2009; 2011b; 2013), and McHugh (2012a).

${ }^{6}$ My own past attempt at solving this problem modeled epistemic reasons on what I called 'hypothetical instrumental reasons', which are like instrumental reasons in pursuit of certain aims, except that they obtain even when the aims are not actually held by the relevant agent. So S has hypothetical instrumental reason to $\phi$ in pursuit of an aim if $\mathrm{S}$ would have instrumental reason to $\phi$ in pursuit of that aim if $S$ had it. As commentators have pointed out, however, it is unclear how hypothetical instrumental reasons could qualify as reasons of the appropriate kind and force. See e.g. Hazlett (2013) and Laurier (2013).
} 


\section{The modality and normative force of epistemic norms}

Obviously, the Too Few Reasons Objection is only effective if it succeeds in citing sound assessments of beliefs that possess a modality and normative force that stands unexplained by the instrumentalist. The objection presupposes that adequate evidence for some proposition invariably provides a positive normative reason to take up belief in the relevant proposition. But this view is becoming increasingly unpopular, even among intrinsicalists. Instead, there is a movement towards regarding evidence as constraining the permissibility of belief, rather than obligating or providing positive reasons for belief. In this section, I sketch this alternative picture, and some of the main reasons to find it attractive. I do not attempt to provide a conclusive argument for it, but merely show that there is an established trend towards it, even among intrinsicalists. If the instrumentalist can account for the epistemic assessments following from this alternative picture, it will therefore seriously detract from the force of the Too Few Reasons Objection.

A popular intrinsicalist line of explanation of epistemic normativity starts from the claim that beliefs are constitutively or essentially subject to a norm of truth, relating the correctness of believing $\mathrm{p}$ to the truth of $\mathrm{p}$. Given this basic norm, intrinsicalists derive evidential norms, according to which beliefs are normatively constrained by the evidence. On this picture, the exact form, modality, and normative force of the truthnorm will have important implications for the evidential norms one might hope to derive. To see this, begin by considering the strong version of the truth-norm, which several philosophers endorse, or used to endorse, according to which the 'correctness' of beliefs is interpreted in terms of what one ought to believe:

\section{Ought: One ought to believe that $\mathrm{p}$ if and only if it is true that $\mathrm{p}$}

If [Ought] is true, we might hope to motivate a correspondingly strong evidential norm, along the following lines:

\section{Ought-e: One ought to believe that $\mathrm{p}$ if and only if one has adequate} evidence that $\mathrm{p}^{9}$

If that is the norm prevailing in the cases of epistemic indifference and avoidance, the instrumentalist is clearly in trouble. But the strong reading of the truth norm has come under heavy fire recently, and many intrinsicalists now prefer weaker versions.

To see why, we can begin by noting that it seems very implausible that we ought to believe any old true proposition, however pointless. A more principled line of argument due to Bykvist and Hattiangadi (2007) point out that while the left-to-right implication absurdly demands us to be omniscient and to believe propositions that cannot even be believed, thus violating the principle that ought implies can, the right-toleft implication doesn't demand anything at all, since it is equivalent to saying that if $\mathrm{p}$ is false, it is not the case that you ought to believe that p. Some have proposed to fix such issues by restricting the norm to propositions that one is currently considering, thus removing the worry that the norm demands belief in propositions that one is not

\footnotetext{
${ }^{7}$ I should note that there is a related but importantly different debate over epistemic permissivism, discussed in e.g. White (2005). The issue in that debate is whether or not the evidence allows only one fully rational doxastic attitude, or permits several equally rational attitudes. By contrast, the issue at present is whether the evidence makes it obligatory or merely permissible to take any attitude at all in response to it. ${ }^{8}$ See e.g. Horwich (1998) and Gibbard (2005).

9 What exactly 'adequate' means need not delay us here. The dispute between instrumentalists and intrinsicalists concerns the normativity of epistemic norms where the central data to be explained by both theories consists in the intuitive requirements placed on us by our evidential situation, so we can take 'adequate' to refer to whatever we would normally deem sufficient evidence for believing $\mathrm{p}$.
} 
interested in or propositions that are too complicated to even consider (e.g. Wedgwood 2002). But this seems to be a rather arbitrary way of delimiting what truths ought to concern us - by simply ignoring a true proposition, you free yourself from any obligation to believe it.

In light of these and other similar considerations, Daniel Whiting (2010; 2013) has proposed what seems to be a much more plausible truth norm, linking truth not to what one ought to believe, but to what one may believe: ${ }^{10}$

May: $\quad$ One may believe that $\mathrm{p}$ if and only if it is true that $\mathrm{p}$

The left-to-right implication of this norm no longer requires us to be omniscient or to believe propositions that we cannot believe, but merely states that believing $\mathrm{p}$ is permissible if $\mathrm{p}$ is true, which seems compatible even with the impossibility of believing p. No less importantly, the right-to-left implication no longer amounts to the nearvacuous claim that it isn't the case that one ought to believe what is not true, but to the much more informative claim that one may not believe what is false.

If [May] or something in its vicinity is as strong a truth norm as we can motivate, what would the corresponding evidential norm be? Certainly, it could be no more demanding than the following (Cf. Whiting 2013: 130):

May-e: $\quad$ One may believe that $\mathrm{p}$ if and only if one has adequate evidence that $\mathrm{p}$

The left-to-right implication of this norm does not demand that we believe everything for which we have adequate evidence, but merely states that believing $\mathrm{p}$ is permissible if we have adequate evidence for $\mathrm{p}$. The right-to-left implication is stricter in stating that it is impermissible to believe what one does not have adequate evidence for.

It is important to note that a case can made for preferring [May-e] over [Ought-e] without consideration of truth norms. In fact, many of the considerations that made [Ought] doubtful apply directly to [Ought-e] as well. At any given point, what I know provides me with conclusive evidence for many more propositions than I could possibly believe, so just as [Ought] did, [Ought-e] seems to violate the principle that ought implies can. As Whiting notes,

\begin{abstract}
Suppose that I have evidence that the cakes are burning. Whatever provides this evidence provides evidence for an infinite number of other beliefs, such as that there are cakes, that the cakes are burning or that Tolstoy wrote Great Expectations, that if the cakes are burning then the cakes are burning, that there is more carbon dioxide in the atmosphere than there was before I made the cakes, that there is no dancing monkey singing the national anthem in the space the cakes occupy, and so on without end. (2013: 130)
\end{abstract}

Whiting goes on to note that since ought implies can, it is not the case that I ought to believe all of these propositions, but at most that I may so believe. But in fact, ought implies can principle seems unnecessary to make the point: surely it is not the case that I ought to go on forming beliefs in as many of these propositions as I possibly can, merely because I have evidence for them. Indeed, this latter consideration reveals a need to qualify the sense of 'permissibility' at play in [May-e]. For in what sense would it really be 'permissible' for someone to embark on the never-ending task of forming beliefs in the kind of trivialities exemplified by Whiting? It would certainly not be permissible in any all

\footnotetext{
10 Other philosophers that explicitly prefer epistemic permissibility norms include Williamson (2000) and Feldman (2000).
} 
things considered sense that would make so doing immune to rational criticism. Indeed, we would not tend to find this particularly rational at all. So the relevant sense of 'permissibility' could only be permissibility as far as the evidence goes, in a way that leaves open that the relevant beliefs are deemed irrational due to other considerations. This point will become important later on.

If [May-e] is the strongest plausible general normative relationship between evidence and belief, this will have serious implications for how we should conceive of evidential reasons for belief. Normative reasons are usually understood as considerations that count in favor of actions or attitudes, or place them in a favorable light, and potentially explain why one ought to take those actions or attitudes, at least in the absence of counterweighing reasons. But if evidence at most affects what beliefs are permissible, it could never on its own constitute a positive reason to adopt a belief. Innumerable things are permissible for me to do at any one time, but this obviously does not give me reason or motivate me to do those things. At most, evidence could be a reason for one to refrain from forming a belief, if a reason is indeed needed for that.

McHugh (2012b) argues that this undermines the plausibility of [May-e], because it is out of line with our ordinary epistemic assessments. It seems that despite the counterexamples to [Ought-e], we are, on at least some occasions, motivated by our evidence to form beliefs, and thus treat our evidence as providing reasons for belief, in a sense that [May-e] is unable to capture. But it is not obvious that the correct response to this observation is to adopt a general principle stronger than [May-e], since the arguments leading us in the direction of [May-e] remain convincing. A better response would be to simply say that while [May-e] is the strongest plausible fully general evidential norm, true of all propositions, there might be some propositions that are such that adequate evidence for them provides or forms part of positive reasons for belief, rather than merely permitting them.

Another possible response would be to think of evidence as something that, in general, provides pro tanto reasons in favor of beliefs, instead of implying an obligation to believe. This would allow the intrinsicalist to claim that in cases such as that exemplified by Whiting above, the evidence does provide reasons for forming beliefs, but only very weak reasons that are easily outweighed by other concerns. But that approach seems hard to accept for any intrinsicalist wanting to claim that epistemic considerations are the only relevant considerations for whether to adopt a belief, since there need not be any evidential difference between cases where there is a strong reason to adopt belief, and cases where the evidence merely provides a weak and easily outweighed reason. Nonepistemic considerations would thus have to be allowed to determine whether the evidence, on the balance of things, provide sufficiently strong reason for forming a belief. $^{11}$

So the picture we end up with is the somewhat complicated one that while the only general and exceptionless way in which the evidence normatively constrain belief is something along the lines of [May-e], occasionally the evidence can provide positive reasons for belief. But the difference between the cases where the evidence does provide reasons, and the cases where it doesn't, isn't itself a matter of the strength of the evidence, but must be explained by some other factor.

As mentioned, my aim here is not to argue conclusively for this picture. It is accepted by at least some intrinsicalists, and, I submit, plausible enough that, if the instrumentalist can account for it, this would significantly reduce the force of the charge that intrumentalism is out of line with our intuitive epistemic assessments. In the next

${ }^{11}$ For further arguments along these lines, see Steglich-Petersen (2008b) 
section, I develop a version of epistemic instrumentalist whose normative assessments of beliefs are in accordance with those following from the above picture.

\section{Instrumentalist epistemic norms}

The aim of the epistemic instrumentalist is to explain our epistemic assessments in terms of general instrumental norms. But what are those general instrumental norms? It is by now common to distinguish between two kinds. ${ }^{12}$ The one kind concerns what has been called 'instrumental rationality', which is a matter of being coherent in one's instrumental attitudes and actions. If one has a certain aim, and believes some means to be necessary to it, one is instrumentally irrational if one refuses to either take the means or give up the aim. But the norms for instrumental rationality in this sense are silent on what one has reason to do. I can exhibit instrumental rationality without intending or doing something that I have instrumental reason to do. This is because adopting a certain aim doesn't by itself give me reason to pursue it. If I have the aim of burning down my neighbor's house, this doesn't by itself give me reason to take what I believe to be the necessary means to do so, even if I would be instrumentally irrational in refusing to take the means while holding on to the aim. On one popular line of thought, this is because instrumental reasons require that one has reasons to adopt the aim in the first place. According to this account, instrumental reasons are a matter of 'transmission' of reasons from aims to means. In addition to coherence norms of instrumental rationality, we thus need principles for when and how instrumental reasons are transmitted in this way.

What I want to suggest in this section is that while the general normative relationship between evidence and belief exhibited by [May-e] can be understood on the model of coherence-norms of instrumental rationality, cases where the evidence provides reasons going beyond mere permissibility, or even obligate belief, can be understood on the model of instrumental transmission. Since the requirement to be instrumentally rational is general or topic neutral, but the existence of instrumentally transmitted reasons varies from case to case, this promises a neat explanation of the puzzling situation arrived at in the above section with a general and exceptionless norm of epistemic permissibility, and a more occasional sense in which evidence sometimes seems to provide positive reasons for belief.

\subsection{Epistemic permissibility as a norm of instrumental rationality}

Begin by considering the explanation of [May-e] as a coherence norm of instrumental rationality. In discussions of instrumental rationality, it is often assumed that instrumental rationality gives rise to wide-scope norms, rather than narrow-scope ones. On the narrow-scope account, if $\mathrm{S}$ has some aim $\mathrm{A}$, and believes that $\phi$-ing is necessary for $\mathrm{A}, \mathrm{S}$ ought to $\phi$. But this has the counterintuitive result that one can sometimes be rationally required to take means to aims that one ought not pursue in the first place. Proponents of the wide-scope account suggest instead that the central demand of instrumental rationality should be understood in terms of requirements that take the entire conditional as its scope, in something like the following way: ${ }^{13}$

Wide scope: $\quad$ S ought to ensure that (if $\mathrm{S}$ has aim $\mathrm{A}$, and believes that $\phi$ ing is necessary for achieving $\mathrm{A}$, then $\mathrm{S} \phi \mathrm{s}$ )

\footnotetext{
12 For more on this distinction, see e.g. Kolodny (forthcoming), and Kolodny \& Brunero (2013).

${ }^{13}$ See e.g. Darwall (1983, 2001), Broome (1999), Dancy (2000), Wallace (2001), and Way (2010).
} 
According to its proponents, this account avoids the counterintuitive result since the requirement is now silent on whether one should comply with it by giving up the aim, or by taking the means to it. As long as the embedded conditional is true, one satisfies the instrumental rationality norm, although not necessarily other kinds of norms, such as norms determining whether to pursue certain aims.

Suppose then that we want to understand [May-e] as an instantiation of the widescope instrumental norm, where the relevant aim is that of believing truly with respect to particular propositions. If we assume for now that in order to ensure true beliefs one must base ones beliefs on adequate evidence, and that this is known to the relevant agent (I will discuss this assumption in a moment), a first stab at this instantiation might be the following norm, which simply substitutes the relevant terms into [Wide scope]:

WS-e 1: $\quad$ S ought to ensure that (if $\mathrm{S}$ has the aim of coming to a true belief as to whether $\mathrm{p}$, and $\mathrm{S}$ believes that basing her belief as to whether $\mathrm{p}$ on adequate evidence is a necessary means to that aim, then $\mathrm{S}$ bases her belief as to whether $\mathrm{p}$ on adequate evidence)

Given this, the crucial question now becomes how [WS-e 1] compares in its normative verdicts to the norm of epistemic persmissibility [May-e]. To allow a more direct comparison, will be helpful first to note that [May-e] is equivalent to the following widescope norm, in the sense that these norms are satisfied and violated under the exact same circumstances:

WS May-e 1: $\quad$ S ought to ensure that (if $\mathrm{S}$ believes that $\mathrm{p}, \mathrm{S}$ has adequate evidence)

[May-e] and [WS May-e 1] are both violated just when S believes that $\mathrm{p}$ and does not possess adequate evidence that $\mathrm{p}$, and are otherwise not violated. Apart from providing independent support for understanding [May-e] as a norm of instrumental rationality, this allows a more direct comparison in the following. That similarity in logical form notwithstanding, there are several obvious differences between [WS May-e 1] and [WS-e 1], some of them relatively superficial, others more serious looking.

To begin with the superficial differences, note first that while the antecedent in [WS May-e 1] mentions a belief that $p$, the antecedent in [WS-e 1] merely mentions an aim of coming to a true belief as to whetherp, and not an actual belief. There is no getting around including an aim in the antecedent clause of the instrumental norm, since that is crucial to the instrumentalist account. I will return to that aim later. But it does seem possible to introduce a belief in the antecedent clause without violating the spirit of the instrumental norm, in the following way:

WS-e 2: $\quad$ S ought to ensure that (if $\mathrm{S}$ believes that $\mathrm{p}$ with the aim of coming to a true belief as to whether $\mathrm{p}$, and $\mathrm{S}$ believes that basing her belief as to whether $\mathrm{p}$ on adequate evidence is a necessary means to that aim, then $\mathrm{S}$ bases her belief adequate evidence)

This principle just extends the demand for instrumental coherence to situations where one is already doing something with a certain aim, but that seems plausible enough. If I am standing in line with the aim of getting a ride, and believe that in order for my standing in line to get me a ride, I must stand in line until I get to the front of it, then I 
better stand in line until I get to the front of it, or else give up standing in line with that aim.

A second relatively superficial difference is in the consequent of the embedded conditionals. While [WS-e 2] has it that $\mathrm{S}$ bases her belief as to whether $\mathrm{p}$ on adequate evidence, [WS May-e 1] simply has it that $\mathrm{S}$ possesses adequate evidence that $\mathrm{p}$. But surely, properly understood, [WS May-e 1] shouldn't simply be taken to require that one possesses adequate evidence, since otherwise the norm would permit believing not based on adequate evidence as long as that evidence is possessed. Allowing this modification to [WS May-e 1] results in the following, which removes the apparent difference:

$$
\text { WS May-e 2: }
$$

$\mathrm{S}$ ought to ensure that (if $\mathrm{S}$ believes that $\mathrm{p}, \mathrm{S}$ bases her belief on adequate evidence)

With this in place, we can move on to the more serious-looking differences. The first is that the instrumental epistemic norm includes reference in the antecedent clause to a belief concerning the necessity of the means to achieving the aim. There are two questions raised by this. First, is plausible to suppose that believing on the basis of adequate evidence is necessary for achieving the aim of true belief? Strictly speaking, it obviously isn't. It is entirely possible to happen upon a true belief by luck, without it being based on any evidence at all, or while being based on inadequate or misleading evidence. But this only shows that we must be careful to understand the intended sense of 'necessary' in the instrumental principle correctly. In discussions of instrumental rationality, the restriction to necessary means is intended to prevent automatic irrationality in case one doesn't take every possible means to some aim, when there are several possible means. For example, if I can get a ride both by standing in line and by bribing the driver, so that neither means is necessary, I shouldn't be deemed irrational for failing to take both of them. But if we interpret 'necessary' in a very strict way, it will be difficult to come up with any examples of genuinely necessary means. Is it necessary to water the plants to keep them alive? In some weak sense yes. But it is almost always possible to imagine odd alternative means that would remove the necessity in the stricter sense. Instead of watering the plants, I might inject them with a new gene that makes it possible for them to extract sufficient moisture from the ambient air, or whatever. So in the present context, by 'necessary' we should presumably mean something along the lines of 'the only practically feasible means with some reasonable level of reliability'. But if that is the intended sense of 'necessary means', it is entirely plausible to suppose that believing on the basis of adequate evidence is necessary for achieving the aim of true belief. There are no other practically feasible means to that aim with a reasonable level of reliability.

The second question raised by the belief-clause concerns what happens when agents fail to have this belief. Before answering this, it should be noted that not believing in the necessity of relying on adequate evidence, at least in some tacit way that disposes one to seek out and rely on evidence, would be extremely detrimental to one's chances in life, not just epistemically. Indeed, it is plausible that such a tacit belief or disposition is to some extent 'hard-wired' by evolution. But what would happen if someone nevertheless failed to believe this? [WS-e 2] would then not deem such a person irrational if she didn't base her belief on adequate evidence as a way of coming to believe the truth. However, if basing one's beliefs on adequate evidence is in fact necessary for achieving true beliefs, it nevertheless seems to be the case that such a person would have conclusive reason to ensure that if she believes that $\mathrm{p}$ with the aim of coming to a true belief as to whether $\mathrm{p}$, then she bases her belief adequate evidence. What one has reason to do is not 
constrained by one's beliefs in the same way as what one rationally ought to do is (Cf. Way 2010).

I shall not pursue this line of thought further here. What is crucial for our purposes is that [WS May-e 2] seems to be subject to the same kinds of considerations. If the agent doesn't believe that basing one's beliefs on adequate evidence is necessary for forming true beliefs, or the agent thinks that beliefs shouldn't be true, or that there are reliable non-evidential ways of coming to true beliefs, or something similarly misguided, it is not obvious that she ought to ensure the truth of the conditional of [WS May-e 2]. In other words, it seems to be a presupposition of [WS May-e 2] that the agent believes that basing one's beliefs on adequate evidence is necessary for ensuring true beliefs. Again, this doesn't rule out that the agent has conclusive reason to ensure the truth of the conditional, even when she doesn't hold that belief. But this reason also stands to be explained by the instrumentalist account, if the above is right. In the following, however, I will hold on to the tacit presupposition of [WS May-e 2] that the agent believes that basing one's beliefs on adequate evidence is necessary for ensuring true beliefs. Granting the same tacit presupposition in the instrumentalist case, we can simplify the instrumental norm to reach the following:

WS-e 3:

$\mathrm{S}$ ought to ensure that (if $\mathrm{S}$ believes that $\mathrm{p}$ with the aim of coming to a true belief as to whether $\mathrm{p}$, then $\mathrm{S}$ bases her belief as to whether $\mathrm{p}$ on adequate evidence)

This leaves us with one last difference: while the antecedent clause in [WS-e 3] includes an aim of coming to a true belief, [WS May-e 2] does not. This means that the two norms differ in their verdicts under exactly one condition, namely when the agent believes $p$ and does not have adequate evidence for $\mathrm{p}$, but also does not aim at coming to a true belief as to whether p. In that case, [WS-e 3] is satisfied, while [WS May-e 2] is violated. In other words, [WS-e 3] allows believing $\mathrm{p}$ in the absence of adequate evidence, so long as one does not aim at a true belief as to whether $\mathrm{p}$. This is the sole extensional difference between [WS-e 3] and [WS May-e 2].

Should the instrumentalist regard this as an unwelcome difference? It might initially seem that way. It certainly seems plausible that there is something wrong with believing $\mathrm{p}$ in the absence of adequate evidence, even when one doesn't aim at believing $\mathrm{p}$ truly. In a moment, I will move on to explain how at least some of these cases can be explained in terms of the transmission of instrumental reasons. But we should also explain why there is something wrong with believing in the absence of evidence even when the agent neither has the aim of truth with respect to the relevant proposition, nor ought or have reason to have that aim.

What sort of wrong would be committed by someone holding such a belief, i.e. a belief ungrounded by evidence in a proposition concerning which one neither aims nor have reason for aiming at believing the truth? Clearly, it would be a rather insignificant wrong, and a wrong that we are all guilty of most of the time to some extent. It would certainly not the kind of wrong that we would typically blame or hold each other personally responsible for, even if a very pervasive tendency towards such beliefs might make us worry about the believer's cognitive ability.

This opens up the possibility that this wrong is explained not by its relation to an intentional aim that the agent has or ought to have, but rather by its relation to the very weak sense in which all beliefs, intentional or otherwise, 'aim' at truth, namely that they are the kind of cognitive states that are regulated by cognitive mechanisms selected by evolution on account of their tendency to ensure true belief. Recall the discussion of the 'aim of belief' strategy in response to the Too Few Reasons Objection. The principal 
problems with this strategy was, first, that is was unable to explain how evidence can provide a reason to take up beliefs that one does not yet have, since no essential aim would be present in such cases either, and, second, that any plausible version of the truth-aim thesis encompassing all beliefs would be too weak to explain the force that we at least sometimes consider epistemic reasons to possess. The first problem is not relevant, since we are now considering the permissibility of beliefs, instead of positive reasons for them. But more importantly, the second problem is also not relevant, since the relevant beliefs are wrong only in a sense that seems minimal enough to be accounted for by the sub-intentional regulation.

The result is that all beliefs are such that they make the believer satisfy the aimclause in the antecedent of [WS-e 3] in the weak sense associated with the 'aim of belief thesis, and that believers in addition to this sometimes satisfy the clause in a stronger sense by holding an intentional aim of believing the truth. ${ }^{14}$ This explanation is somewhat untidy in implying that not all beliefs are right or wrong in the same sense, and that they can be right or wrong in several senses at once. Some are right/wrong in the sense of succeeding/failing to serve an intentional aim that an agent has. Others are right/wrong merely in the very weak sense of succeeding/failing in achieving what the mechanisms regulating beliefs are selected for by evolution to achieve. As we shall see in the following section, others still are right/wrong in the sense of succeeding/failing in serving an aim that the agent has reason to or ought to have. But why should we expect things to be tidier than this? Instrumental actions can also be right or wrong in at least two senses, namely right/wrong in the sense of succeeding/failing to serve a personal or intentional aim that an agent has, and in the sense of succeeding/failing in serving an aim that the agent ought to have. Beliefs are psychological states under regulation by mechanisms with a particular evolutionary history, and can be evaluated as such as well, but that should not in itself be particularly troubling.

In sum, it seems that the epistemic norm of permissibility [May-e] and the epistemic instantiation of the wide-scope norm for instrumental rationality are much closer in their verdicts that they initially seemed to be, and that the remaining difference doesn't commit the instrumentalist to obviously counterintuitive results. It thus seems plausible to explain the permissibility norm, or at least the intuitive assessments motivating that norm, in terms of the norm for instrumental rationality.

\subsection{Epistemic reasons and instrumental transmission}

This leaves us with the task of explaining the cases where the evidence seems to provide positive reasons going beyond mere permissibility, or even to obligate belief. The hypothesis that I will pursue here is that these cases can be understood on the model of instrumental transmission of reasons from aims to means.

It is debated how to best formulate the transmission principle for instrumental reasons in general. The basic underlying intuition is that reasons to take means depends on the reasons one has to pursue the aims that they contribute to, and that the strength or force of instrumental reasons tracks the strength of the reasons for pursuing aims, at least in part. One way of capturing this, recently proposed by Kolodny (forthcoming), which is also designed to avoid a number of standard problems and counterexamples, is the following:

\footnotetext{
${ }^{14}$ For more on this distinction between two different ways of aiming at truth, see Steglich-Petersen (2006a).
} 
Transmission: If there is reason for one to pursue aim $A$, and there is positive probability conditional on one's $M$-ing, that this helps bring about $A$ nonsuperflously, then that is a reason for one to $M$, whose strength depends on the reason for one to $A$ and the probability. ${ }^{15}$

Kolodny notes that he favors an epistemic interpretation of the notion of probability at play, i.e. "where the possible outcomes $[\ldots]$ are ways things might be relative to a relevant body of information, and where the probabilities assigned to those outcomes are likewise fixed by that body of information" (forthcoming: 5). What is the relevant body of information? Presumably, it is the agent's total evidence, since no other alternative makes sense of the interpretation: if it was all relevant information, the probability would reduce to the objective chance; and any other limited body of information apart from the agent's total evidence would be arbitrary. So the relevant conditional probability is that resulting from conditionalising on the fact that one $M$ s together with one's total evidence.

How can this principle explain the cases where the evidence not only permits belief, but provides positive reason for or even obligate belief? Consider the following instantiation of [Transmission]:

Transmission-e: If there is reason for one to pursue the aim of coming to a true belief as to whether $\mathrm{p}$, and there is positive probability conditional on one's adopting a belief that $\mathrm{p}$, that this helps bring about that aim nonsuperflously, then that is a reason for one to adopt a belief that $\mathrm{p}$, whose strength depends on the reason for one to pursue the aim and the probability.

To illustrate, I might have a strong reason to pursue the aim of coming to a true belief as to whether my chemical lawn repair kit has harmful effects on the environment. If there is positive probability that adopting a belief that it does have harmful effects nonsuperflously helps bring about a true belief on the matter (i.e. by constituting it), conditional on my total evidence plus the belief, then that gives me a reason to do adopt such a belief, whose strength depends on the strength of the reason to pursue a true belief about the matter, and how likely it is to achieve the aim.

A consequence of this proposal is that evidence plays the exact same role in transmitting reasons for belief, and reasons for instrumental actions. In both cases, the evidence determines a probability that the belief or action will be successful, relative to the aim that one has reason to pursue. That probability then partly determines the strength of the transmitted instrumental reason.

No doubt, [Transmission-e] will require some fine-tuning, which I have to leave for another occasion. But if something along those lines is correct, we seem well placed to explain cases where the evidence provide positive reasons for belief, since it is plausible to suppose that in all such cases, there is a reason of an ordinary practical kind to pursue a true belief about the relevant proposition. The evidence will then form part of the reason for belief, along with the reason for pursuing a true belief.

\footnotetext{
${ }^{15}$ Kolodny (forthcoming). The principle has been adjusted to conform to my preferred terminology.
} 


\subsection{Too Many Reasons?}

Before closing, I want to discuss a possible objection to the above account, which is in effect a version of the Too Many Reasons Objection, which I mentioned earlier but haven't discussed so far. The objection is that being subject to the proposed epistemic instantiations of the wide-scope and transmission norms above is compatible with simultaneously being subject to different instantiations of those norms enjoining one to sometimes ignoring the evidence when forming beliefs, for example when one aims at believing some proposition regardless of its truth, or has reason to do so, such as the following:

WS-e*:

Transmission-e*:
$\mathrm{S}$ ought to ensure that (if $\mathrm{S}$ believes that $\mathrm{p}$ with the aim of believing $\mathrm{p}$ regardless of the truth of $\mathrm{p}$, then $\mathrm{S}$ ignores the evidence as to whether $\mathrm{p}$ )

If there is reason for one to pursue the aim of believing $\mathrm{p}$ regardless of the truth of $\mathrm{p}$, and there is positive probability conditional on one's ignoring the evidence as to whether $\mathrm{p}$, that this helps bring about that aim nonsuperflously, then that is a reason for one to ignore the evidence as to whether $\mathrm{p}$, whose strength depends on the reason for one to pursue the aim and the probability.

While these norms seem like perfectly good instrumental advice, they seem to violate normal intuitions about the permissibility of and reasons for belief. Nevertheless, neither should be seen as objections against the instrumentalist account. Consider first [WS-e*]. Since that norm is silent as to whether one should conform to it by taking the means or giving up the aim, the norm will only violate normal intuitions when there is reason to hold on to the aim. The same is the case for [Transmission-e*], which will only recommend ignoring the evidence, when there is reason for one to pursue a belief that $\mathrm{p}$ regardless of the truth of $\mathrm{p}$. These norms are therefore likely to be dialectically ineffective in arguments against the instrumentalist on behalf of the intrinsicalist. For suppose that we sometimes do have genuine reason to seek a false belief as to whether $\mathrm{p}$, or to believe that $\mathrm{p}$ regardless of p's truth. In that case, the norms will indeed generate instrumental advise to ignore the evidence as to whether $\mathrm{p}$, which would go against our normal intuitions. But if the reasons to seek false beliefs are indeed genuine reasons, this is something that the intrinsicalist must explain as well, in which case the absolute reading of [May-e]'s prohibition of beliefs in the absence of adequate evidence would come under pressure. If, on the other hand, we never have genuine reasons to seek false beliefs, or to believe regardless of the truth, then the absolute reading of [May-e]'s prohibition of evidentially ungrounded beliefs stands. But in that case, this will be compatible with the instrumentalist account, since we will never be able to detach a reason to ignore the evidence in forming beliefs. If we never have reason to adopt the aim in the alternative instrumentalist norms, we will also never have instrumental reason to ignore the evidence. The fact that instrumental reason requires us to ignore the evidence if we aim or ought to aim at believing that $\mathrm{p}$ regardless of p's truth is perfectly compatible with that.

\section{Conclusion}

To summarize, although much more could be said on the above account, I hope to have made it sufficiently plausible that once we realize that [May-e] is the strongest tenable 
general normative relationship between evidence and belief, and that evidence only occasionally provides positive normative reasons for belief, it is no longer so obvious that the instrumentalist account cannot deliver the right normative verdicts. The epistemic norm of permissibility can be understood as an instantiation of the wide-scope norm of instrumental rationality, and cases of positive evidential reasons can be understood on the model of instrumental transmission. Some readers may object that the debate on whether the strongest plausible general epistemic norm merely permits and forbids belief, is less settled than indicated here. If so, I still contend that an important conditional claim has been motivated: if it turns out that this is indeed the strongest plausible general epistemic norm, then the instrumentalist can deliver the right epistemic verdicts. ${ }^{16}$

\section{References}

Adler, Jonathan (2002). Belief's Own Ethics. MIT Press.

Broome, John (1999). Normative Requirements. Ratio 12: 398-419.

Bykvist, K and A. Hattiangadi (2007). Does thought imply ought? Analysis 67: 27785.

Côté-Bouchard, Charles (2015). Epistemic Instrumentalism and the Too Few Reasons Objection. International Journal of Philosophical Studies 23: 337-55.

Cowie, Christopher (2014). In Defence of Instrumentalism About Epistemic Normativity. Synthese 191: 4003-17.

Dancy, Jonathan (2000). Practical Reality. Oxford University Press.

Darwall (1983). Impartial Reason. Cornell University Press.

- (2001). Because I want it. Social Philosophy and Policy 18: 129-53.

Engel, Pascal (2004). Truth and the Aim of Belief. In D. Gillies (ed.), Laws and Models in Science, London: King's College Press, 77-97.

Fassio, Davide (2011). Belief, Correctness and normativity. Logique Et Analyse 54: 471.

Feldman, Richard (2000). The ethics of belief. Philosophy and Phenomenological Research 60: 667-95.

Foley, Richard (1987). The Theory of Epistemic Rationality. Harvard University Press.

Gibbard, Alan (2005). Truth and Correct Belief. Philosophical Issues 15: 338-50.

Giere, Ronald (1989). Scientific rationality as instrumental rationality. Studies in History and Philosophy of Science 20: 377-84.

Hattiangadi, Anandi (2007). Oughts and Thoughts: Rule-Following and the Normativity of Content. Oxford University Press.

Hazlett, Allan (2013). A Luxury of the Understanding: On the Value of True Belief. OUP Oxford.

Horwich, Paul (1998). Meaning. Oxford University Press.

Kelly, Thomas (2003). Epistemic rationality as instrumental rationality: a qritique. Philosophy and Phenomenological Research 66: 612-40.

Kitcher, Philip (1992). The Naturalist's Return. The Philosophical Review 101: 53-114.

Kolodny, Niko (forthcoming). Instrumental reasons. In: Daniel Star (ed.), The Oxford Handbook of Reasons and Normativity. Oxford University Press.

Kolodny, Niko, and John Brunero (2013). Instrumental Rationality. The Stanford

\footnotetext{
${ }^{16}$ I wish to thank the editors of this volume, and participants at the January 2015 Normativity Workshop at the University of Southampton for helpful comments and criticism.
} 
Encyclopedia of Philosophy.

Laurier, Daniel (2013). Les raisons épistémiques sont-elles instrumentals? Dialogue 52: 211-31.

Mackie, J.L. (1979). Ethics: Inventing Right and Wrong. Penguin Press.

McPherson, T. (2012). Mark Schroeder's Hypoheticalism: Agent Neutrality, Moral Epistemology, and Methodology. Philosophical Studies 157: 445-53.

McHugh, Conor (2012a). Belief and aims. Philosophical Studies 160: 425-39.

- (2012b). The Truth Norm of Belief. Pacific Philosophical Quarterly 93: 8-30.

Nozick, Robert (1993). The Nature of Rationality. Princeton University Press.

Olson, Jonas (2011). 'Error Theory and Reasons for Belief'. In A. Reisner and A. Steglich-Petersen (eds.), Reasons for Belief. Cambridge University Press.

Papineau, David (1999). Normativity and Judgment. Proceedings of the Aristotelian Society, supplementary vol. 22: 17-41.

Parfit, Derek (2011). On What Matters. Oxford University Press.

Quine, W.V. (1969). Epistemology Naturalized'. In Ontological Relativity and Other Essays. Columbia University Press.

Scanlon, T.M. (1998). What We Owe to Each Other. Harvard University Press.

Schroeder, Timothy (2007). Slaves of the Passion. Oxford University Press.

Shah, Nishi (2003). How truth governs belief. Philosophical Review 112 (4):447-482.

Steglich-Petersen, Asbjørn (2013). Transparency, Doxastic Norms, and the Aim of Belief. Teorema 32.

- (2011a). How to be a teleologist about epistemic reasons. In Asbjørn SteglichPetersen \& Andrew Reisner (eds.), Reasons for Belief. Cambridge University Press. 13--33.

- (2011b). Against Essential Mental Normativity Again. Dialogue 50 (02):333-346.

- (2009). Weighing the aim of belief. Philosophical Studies 145 (3):395 - 405.

- (2008a). Against essential normativity of the mental. Philosophical Studies 140 (2):263 - 283 .

- (2008b). Does doxastic transparency support evidentialism? Dialectica 62 (4):541547.

- (2006a). No Norm needed: On the aim of belief. Philosophical Quarterly 56 (225):499-516.

- (2006b). Voluntarism and Transparent Deliberation. South African Journal of Philosophy 25 (2):171-176.

Velleman, David (2000). On the aim of belief. In The Possibility of Practical Reason. Oxford University Press. 244--81.

Wallace, R. Jay. (2001). Normativity, Commitment, and Instrumental Reason. Philosophers' Imprint 1(3).

Way, Jonathan (2010). Defending the wide-scope approach to instrumental reason. Philosophical Studies 147: 213-233.

Wedgwood, Ralph (2002). The Aim of Belief. Philosophical Perspectives 16: 267-97. - (2007). The Nature of Normativity. Oxford University Press.

White, Roger (2005). Epistemic Permissiveness. Philosophical Perspectives 19:14559.

Whiting, Daniel (2010). Should I Believe the Truth? Dialectica 64 (2):213-224.

- (2013). Truth: the Aim and Norm of Belief. Teorema 32: 121-36.

Williams, Bernard (1973). Deciding to Believe. In Problems of the Self. Cambridge: Cambridge University Press, 136-52.

Williamson, Timothy (2000). Knowledge and its limits. Oxford University Press. 